\title{
Ecological characteristics of a recently described, critically endangered gecko species, endemic to Central Highland, Vietnam
}

\author{
Vinh Quang Luu ${ }^{1}$, Oanh Lo Van ${ }^{1}$, Tuoi Thi Hoang ${ }^{1}$, Thong Pham Van ${ }^{2,3}$, Olivier Le Duc ${ }^{2,3}$, \\ Cedric Bordes ${ }^{2,3}$, Benjamin Leprince ${ }^{2,3}$, Giovanni Amori ${ }^{4}$ and Luca Luiselli $i^{5-7^{*}}$ \\ ${ }^{1}$ Vietnam National University of Forestry, Xuan Mai town, Chuong My district, Hanoi, Vietnam; \\ ${ }^{2}$ Turtle Sanctuary and Conservation Center, Paris, France; ${ }^{3}$ Associated Wildlife and Environment \\ Conservation Community AWECC, Paris, France; ${ }^{4}$ Research Institute on Terrestrial Ecosystems, \\ CNR, Rome, Italy; ${ }^{5}$ Institute for Development, Ecology, Conservation and Cooperation, Rome, \\ Italy; ${ }^{6}$ Department of Applied and Environmental Biology, Rivers State University of Science and \\ Technology, Port Harcourt, Nigeria; ${ }^{7}$ Département de Zoologie et Biologie Animale, Faculté des \\ Sciences, Université de Lomé, Lomé, Togo
}

Received for publication: 7 June 2020; Accepted for publication: 2 September 2020.

\begin{abstract}
Gia Lai bent-toed gecko (Cyrtodactylus gialaiensis) was firstly described in 2017 , and is an endemic species with very restricted distributional range, estimated to be less than $10 \mathrm{~km}^{2}$ in coffee plantation in Gia Lai province, Central Highland of Vietnam. This species is listed as Critically Endangered (CR) in the IUCN Red List. To date, the natural history of this species is totally unknown. In this paper, we provide the first-of-ever natural history data on this highly threatened gecko species, with emphasis on morphometrics, habitat preferences, thermal ecology, and activity patterns. In 23 days of surveys, we captured 42 C. gialaiensis individuals and recaptured 4 of them. Sex ratio was not skewed from equality and juveniles accounted for $23.8 \%$ of the observed individuals. The two sexes did not differ in terms of mean Snout-to-Vent Length, Tail Length and weight, but the adult females had longer head than adult males. Geckos were observed at a mean substratum temperature of $24.2 \pm 1^{\circ} \mathrm{C}(\mathrm{n}=14)$, and exhibited a mean body temperature of $29.5 \pm 2.5^{\circ} \mathrm{C}(\mathrm{n}=14)$. There was no significant correlation between substratum and body temperatures. Body temperatures were significantly higher than substratum temperatures. The study species exhibited a clearly nocturnal above-ground activity, with main peak occurring between 20:00-21:30 h.
\end{abstract}

Key words: Endemic species; Gekkonidae; natural history; Vietnam.

\section{Introduction}

Vietnam is a mega-diverse country in terms of lizard species richness, and includes also many endemic species (e.g., Ngo et al. 2016, 2018; Xiao et al. 2017). However, only very few studies were conducted on the natural history of the various endemic lizard species in Vietnam, and almost nothing is known on their habitat selection, population

\footnotetext{
*Corresponding author. E-mail: 1.luiselli@ideccngo.org ; lucamaria.luiselli@ubiroma3.it
}

${ }^{\circ}$ Copyright: the Author(s), 2020 | Licensee PAGEPress, Italy 
size, thermal ecology, and diet (Huang and Ning 2006; Huang 2006; Ngo et al. 2016, 2018; Xiao et al. 2017).

The genus Cyrtodactylus Gray, 1827 (bent-toed geckos) is the most speciose of the Gekkonidae family, with 296 species recognized globally (Reptile database 2020). However, the list of Cyrtodactylus species is incomplete as many new species have been described during the last 10 years. For instance, during the period 2017-2020, 64 new species of Cyrtodactylus were described around the world (Luu et al. 2017; Uetz 2020), many of them from Asia (Nguyen et al. 2006, 2010, 2015; Schneider et al. 2011; David et al. 2011; Panitvong et al. 2014; Luu et al. 2017), including also 12 species that were recently described from Myanmar (e.g., Grismer et al. 2018a, 2018b). Vietnam houses 43 species of Cyrtodactylus and is therefore a hotspot of diversity for the bent-toed geckos, with many species being endemic (Nguyen et al. 2015; Uetz 2020). As regards the ecological aspects of the endemic geckos, however, very little is known, despite these data would be essential also in order to implement reliable conservation plans for these endemic and often threatened species.

The Gia Lai bent-toed gecko Cyrtodactylus gialaiensis Luu, Dung, Nguyen, Le \& Ziegler, 2017 is an endemic species with very restricted distributional range, estimated to be less than $10 \mathrm{~km}^{2}$, in coffee plantations of the Gia Lai province, Central Highland of Vietnam (Luu et al. 2017; Luu 2018). The species is listed as Critically Endangered (CR) in the IUCN Red List (2020) due to several threats, and especially habitat conversion and the risk of predation by domesticated animals (chickens, cats, dogs, etc.), other than by the very small range area (Luu 2018). The natural history of this species is still totally unknown. In this paper, by studying in the wild the only known population of the species in Gia Lai province, Central Highland of Vietnam, we provide the first-of-ever natural history data on this highly threatened gecko species. More specifically, we focus on morphometrics, habitat preferences, thermal ecology, and activity patterns.

\section{Materials and methods}

\section{Study area}

The field survey was conducted in different habitats in Chu Se, Krong Pa, Phu Thien, Chu Prong districts, Gia Lai province in Central Highland of Vietnam (Figure 1). Due to conservation reasons, we do not provide here the details of the geographic coordinates of the precise sites. The elevation range was from 253 to $767 \mathrm{~m}$ a.s.1.; there were two main seasons in the province: wet season from May to October, and dry season from November to April. The province is a main place for the production of coffee, rubber and pepper. In Chu Se district only, there are about nearly 2000 ha land for rice field, 10086 ha of coffee plantation, 3649 ha of pepper plantation, and over 1000 ha of fruits (durian, banana, jack fruit, etc.) (Chu Se People Committee 2019).

\section{Protocol}

The field surveys were carried out by two researchers on each study site. In total, 23 days of searching, from $8^{\text {th }}$ February to $4^{\text {th }}$ March 2020, were spent in the field. During the first days of survey, we searched for these lizards in coffee, rubber and pepper plantations at Chu Se district, i.e. in the same sites where the species was found for the first time and described in 2017 (Luu et al. 2017). After these first days of survey, the team explored also other habitats, and especially focused on surveying the protected forests in Chu Se, Krong Pa, Phu Thien and Chu Prong districts of Gia Lai province, where the presence of the study species 
was supposed and in order to confirm whether $C$. gialaiensis has a larger range than presently known (Luu 2018). In general, the study region was a mixture of coffee, rubber and pepper plantations interspersed with natural forest dominated by species of Dipterocapaceae.

We surveyed $C$. gialaiensis by walking along seven different transects throughout the following different habitats types:

i) Coffee plantation. It was a flatten land planted monoculture crops of coffee tree (age: 3-15 years old with about tree height is about 1-2 m). Coffee trees were planted in lines, each line about 3-4 $\mathrm{m}$ in distance. Around the coffee root, the farmers dug holes in order to keep water for irrigation.

ii) Rubber plantation. It was a land planted only with rubber trees about 10 years old, and with a height of 4-7 m. Rubber trees were planted along lines, about 4-5 $\mathrm{m}$ in distance from each other.

iii) Pepper plantation. Pepper plants were also placed along lines, $2 \mathrm{~m}$ in distance between adjacent lines.

iv) Rice field cliff. It consisted of some small rice fields with several soil cliff potentially available to geckos.

v) Mature forest. It is a natural deciduous forest with mainly dipterocarp trees (Dipterocarpaceae) situated in the Chu Prong district.

vi) Secondary forest. It was an altered forest situated in the in Krong Pa district. This forest consisted of relatively small trees, and was about $100 \mathrm{~km}$ away from the site of first discovery and description for $C$. gialaiensis.

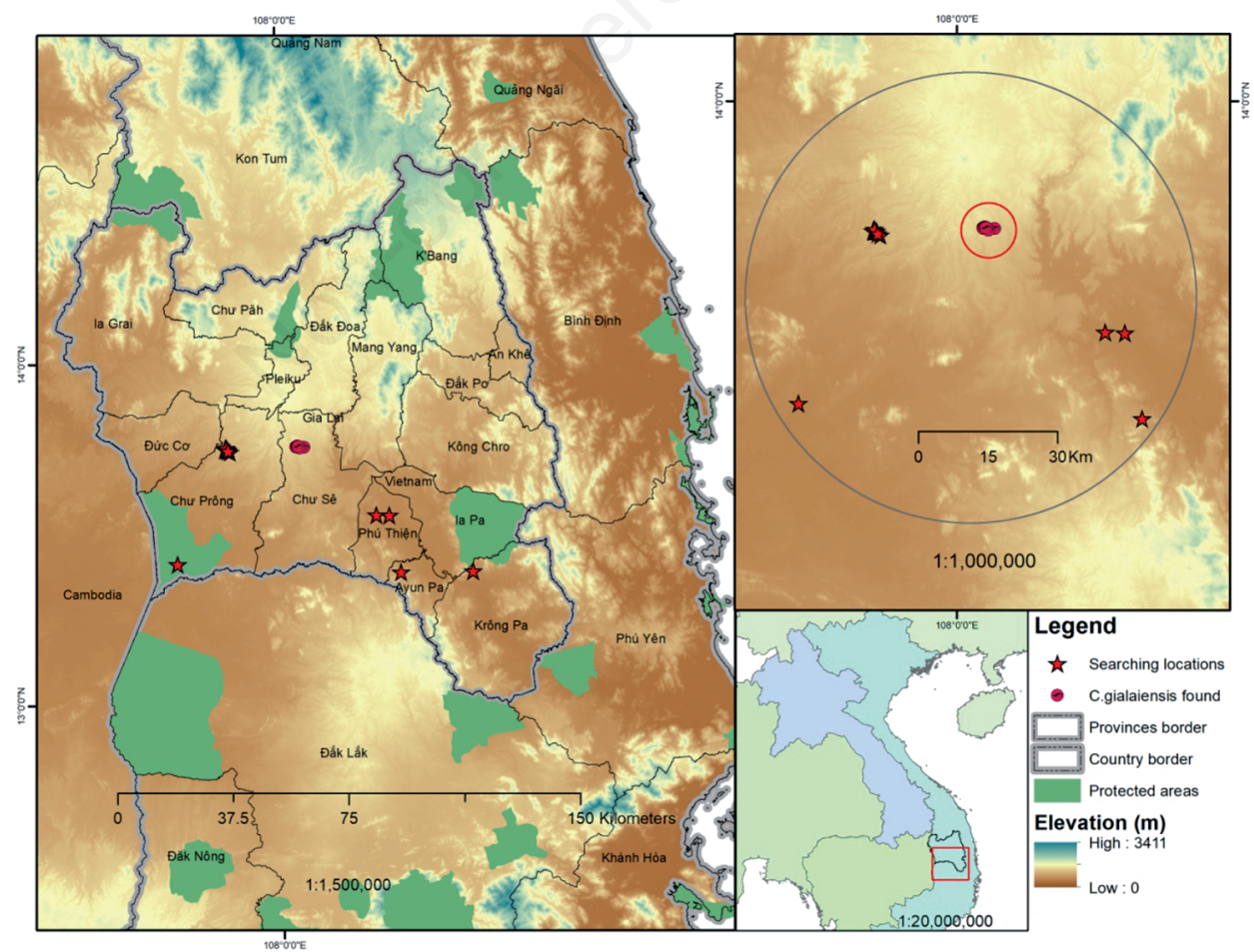

Figure 1. Map of the study area showing the sites of observation for Cyrtodactylus gialaiensis in northern Vietnam. 
vii)Roadside soil cliff. This habitat separated the coffee plantation from the rubber plantation. The cliff was made because people dug the soil from the side and from a small hill to build the road. The cliff height was 0.3 to $2.5 \mathrm{~m}$. The vegetation along the road was coffee trees on one side, rubber trees on the other side with grasses and few trees (Melia azedarach). The cliff was characterized by many holes and crevices in the red soil, which is typical basaltic soil.

In total, we spent almost 76 hours in the field and covered a total of $40.5 \mathrm{~km}$ of transect length. The time spent in each habitat type was approximately the same. We searched for lizards mainly from 18:30 to 23:00 (Hanoi time). If a C. gialaiensis individual was found, it was captured by hand and its body length (SVL, mm), tail length ( $\mathrm{mm})$, and head length $(\mathrm{mm})$ were measured by using a caliper $( \pm 0.1 \mathrm{~mm})$, and it was weighed with a spring scale (Tesso Digital Mini Pocket Scale, $200 \pm 0.01 \mathrm{~g}$ ). We also recorded its body temperature immediately once the animal was observed from about $1 \mathrm{~m}$ distance, and the ground temperature data at the site of sighting. Both temperatures were recorded by infrared thermometer Etekcity). We also recorded the GPS coordinates of the capture site by GPS Garmin 60CSX. In order to avoid pseudo-replication, we marked the various captured $C$. gialaiensis individuals by painting their back/legs with correction fluid. We also re-walked repeatedly the same transects in order to calculate the mark/recapture rate of the study species.

Sex-ratio departure from 1:1 was assessed by observed-versus-expected $\chi^{2}$ test. We also evaluated by observed-versus-expected $\chi^{2}$ test the differences in the frequencies of observed geckos among nine 30-minutes intervals of field research (from 18 to $23 \mathrm{~h}$ ). We evaluated the intersexual differences in terms of morphometric measurements and weight by Student t-test.

We carried out the correlation between substratum and body temperatures by a Pearson product moment correlation coefficient. Employing the properties of the Central Limit Theorem, that determines that (i) the mean of the sample means will be the mean of the population and (ii) avoids pseudoreplication and inflating the degrees of freedom (Lombardi and Hulbert 1996), we used the means of substratum temperatures as the independent variables (T0), and the differences between mean substratum temperatures and mean body temperatures $(\mathrm{Tb})$ as the dependent variables. This gives an equation of the form:

$$
\mathrm{Tb}-\mathrm{T} 0=m \mathrm{~T} 0+b
$$

where $m$ is the regression coefficient and $b$ the y-intercept (Meek 2005). In this test, no thermoregulation is indicated when $\mathrm{Tb}-\mathrm{T} 0=0$ and $m=0$, and it can be evaluated by comparison against a hypothetical regression coefficient of 0 using a t-test at $n-2$ degrees of freedom (Bailey 1981). In this case, $m=0$ would mean no thermoregulation. Significant departures from 0 therefore provide evidence of thermoregulation (Meek 2005).

In order to calculate the population size of the study species, we applied the following formula (Huang et al. 2008):

$$
N=\sum[m *(1+i)]
$$

With $N=$ Population size, $m=$ total number of individuals observed, and $i$ being the so-called "invisibility rate". The invisibility rate was calculated by the following formula (Huang et al. 2008):

$$
i=\sum(b n-a n) / \sum a n
$$

With an being the number of observed individuals along transect $n$ during the first survey, 
and $b n$ being the total number of observed individuals along transect $n$. Both an and $b n$ should be applied to transects that were repeated at least once (i.e. at least two walks in total).

We evaluated the correlation between daily field effort (in minutes) and number of observed geckos by the nonparametric Spearman's rank correlation coefficient. Mean differences between substratum and body temperatures of lizards were evaluated by Mann Whitney U-test, as substratum temperatures were non-normal (Shapiro-Wilk W, $\mathrm{P}<0.05$ ). All statistical analyses were performed with Past 3.0 statistical software, with alpha set at $5 \%$. In the text, means are followed by \pm 1 Standard Deviation.

\section{Results}

After 23 days of intensive survey, we captured 42 individuals of C. gialaiensis and recaptured 4 of them (see the synopsis of the collected data in the Online Supplementary Table S1). We also captured several other species in the various surveyed sites: Cyrtodactylus taynguyenensis Nguyen, Le, Tran, Orlov, Lathrop, MacCulloch, Le, Jin, Nguyen, Nguyen, Hoang, Che, Murphy \& Zhang, 2013, Cyrtodactylus sp., Hemidactylus frenatus Schlegel in Duméril \& Bibron, 1836, Gekko gekko (Linnaeus, 1758), Gekko palmatus Boulenger, 1907, Calotes emma Gray, 1845, and the snakes Bungarus multicinctus Blyth, 1861, Indotyphlops braminus (Daudin, 1803), Dixonius sp., Oligodon chinensis (Günther, 1888) and Boiga multomaculata (Boie, 1827) (Online Supplementary Table S2 and Figure S1). Compared to those reptiles, it was seen that $C$. gialaiensis was the most commonly encountered species accounting for $53.8 \%(n=78)$ of the individual sightings. Nonetheless, $C$. gialaiensis was found in only two of the seven types of habitat: the soil cliff on road side between coffee plantation and rubber plantation (habitat (7) in the methods, $88.1 \%, n=42$ ) and the coffee plantation (habitat (1) in the methods, $11.9 \%$ ) (Figure 2). The distance of $C$. gialaiensis individuals from the pepper plantation habitat was about $1000 \mathrm{~m}$, from rice field was $800-900 \mathrm{~m}$.

There was no correlation between daily field effort and number of observed geckos $\left(r_{S}=0.186, P=0.395\right)$. Sex ratio was not skewed from equality (1.44: 1 , male: female; $\chi^{2}=2$, $d f=1, P=0.157)$, with juveniles representing $23.8 \%$ of the observed individuals. The two sexes did not differ in terms of mean $\operatorname{SVL}(t=1.57, P=0.128)$, tail length $(t=-1.69, P=0.106)$ and weight $(t=1.53, P=0.138)$, but the adult females had a significantly longer head than adult males $(t=2.29, P<0.05)$. Morphometric measurements for the various population groups (males, females and juveniles) are presented in Table 1. The total population size (number of adults) was estimated at 117 (Table 2).

Geckos were observed at a mean substratum temperature of $24.2 \pm 1^{\circ} \mathrm{C}(n=14)$, and

Table 1. Synopsis of the morphometric data taken from a sample of Cyrtodactylus gialaiensis from the study area in Vietnam.

\begin{tabular}{lcccccc} 
& \multicolumn{2}{c}{ Males } & \multicolumn{2}{c}{ Females } & \multicolumn{2}{c}{ Juveniles } \\
& Mean (SD) & Range & Mean (SD) & Range & Mean (SD) & Range \\
SVL $(\mathrm{mm})$ & $54.78(5.33)$ & $46.75-63.42$ & $58.85(8.61)$ & $46.87-74.15$ & $39.08(4.83)$ & $32.18-45.79$ \\
\hline tail length $(\mathrm{mm})$ & $54.74(8.31)$ & $35.38-68.12$ & $60.23(8.63)$ & $46.98-71.5$ & $44.47(7.88)$ & $32.96-54.84$ \\
\hline Head length $(\mathrm{mm})$ & $17.29(1.55)$ & $14.25-19.5$ & $18.79(1.98)$ & $15.7-21.67$ & $13.6(3.02)$ & $11.38-21.19$ \\
\hline Weight $(\mathrm{g})$ & $4.46(1.25)$ & $2.78-7$ & $5.62(2.79)$ & $2.74-11$ & $1.75(0.91)$ & $1.0-4.0$ \\
\hline Total & $\mathrm{n}=17$ & $\mathrm{n}=12$ & $\mathrm{n}=9$ & \\
\hline
\end{tabular}


exhibited a mean body temperature of $29.5 \pm 2.5^{\circ} \mathrm{C}(n=14)$. There was no significant correlation between substratum and body temperatures $(r=0.29, P=0.322$; Figure 3$)$. In addition, the results were against $m=0$ (a perfect thermoregulator gecko): $m=0.53, t=1.03$,

Table 2. Synthesis of the population size parameters, calculated from the field data collected at the various transects of the study area, for Cyrtodactylus gialaiensis in Vietnam. Total population size was calculated from Huang et al. (2008).

\begin{tabular}{lccc} 
& an & $b n$ & bn-an \\
Transect 2 & 4 & 10 & 6 \\
\hline Transect 12 & 3 & 14 & 11 \\
\hline Transect 14 & 3 & 5 & 2 \\
\hline Transect 15 & 4 & 10 & 6 \\
\hline Total number & 117 & &
\end{tabular}

Abbreviations: $\mathrm{an}=$ number of observed individuals along transect $\mathrm{n}$ during the first survey; $\mathrm{bn}=$ total number of observed individuals along transect $\mathrm{n}$.

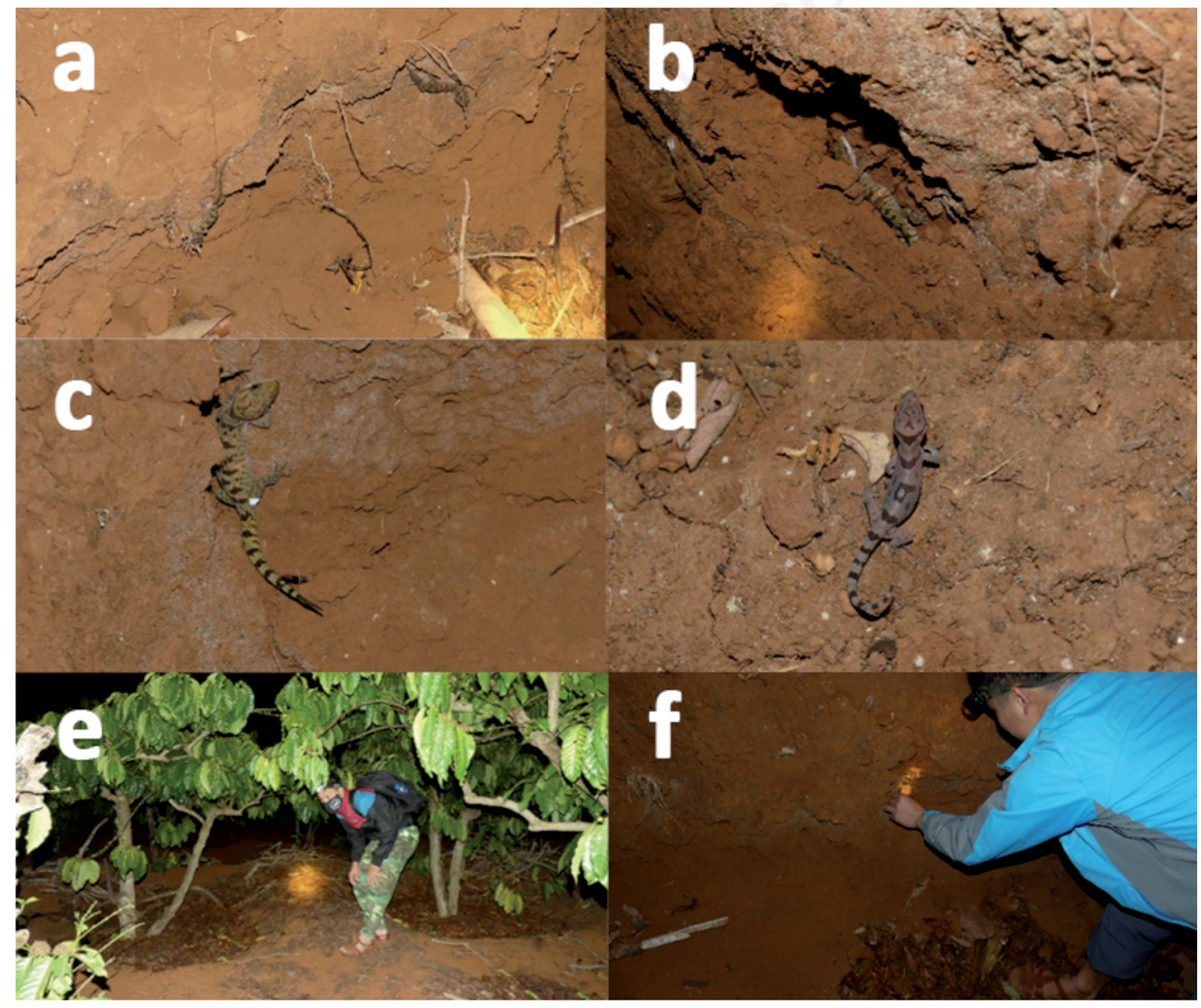

Figure 2. Several images of Cyrtodactylus gialaiensis in the wild, where the species often hide inside small holes in the cliff: a) two adults of $C$. gialaiensis at the study site. b) a hole where the adult hides itself. c) adult (numbered 4) with the mark on right hind leg. d) a juvenile found at night. e) coffee plantation habitat where $C$. gialaiensis was found. f) the soil cliff habitat where $C$. gialaiensis were frequently observed. All photos: Lo Van Oanh. 
$P=0.32$, so there was statistical agreement of 0.53 with 0 . This is supported by body temperatures significantly higher than substratum temperatures (Mann Whitney $U$-test, $W=107, P<0.00001)$.

The studied species exhibited a clearly nocturnal above-ground activity, with main peak occurring between 20:00-21:30 h (Figure 4). The earliest record of an above-ground active gecko was at 19:40 h, and the latest was at 22:50 h (but we suspended searching by 23:00 h). Overall, the frequencies of observed geckos differed statistically among the various 30minutes intervals, with the peak between $20-20: 30 \mathrm{~h}$ being significant $\left(\chi^{2}=39.7, d f=8, P\right.$ $0.0001)$.

\section{Discussion}

Despite being preliminary, our study is the first scientific research documenting aspects of the ecology in the wild of $C$. gialaiensis, that is one of the gecko species with the narrowest range in the world. In terms of ecological characteristics, $C$. gialaiensis was not remarkably different from any other Cyrtodactylus (Bauer 2013): it is nocturnal, with even sex-ratio, lack

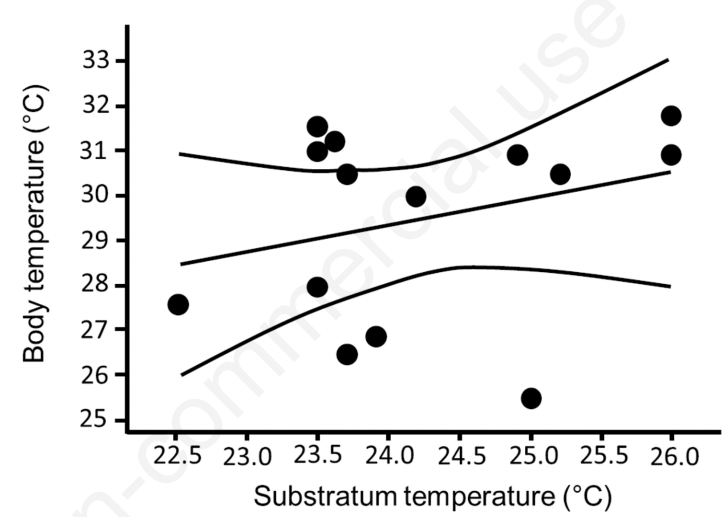

Figure 3. Correlation between body and substratum temperatures in Cyrtodactylus gialaiensis from the study area in Vietnam.

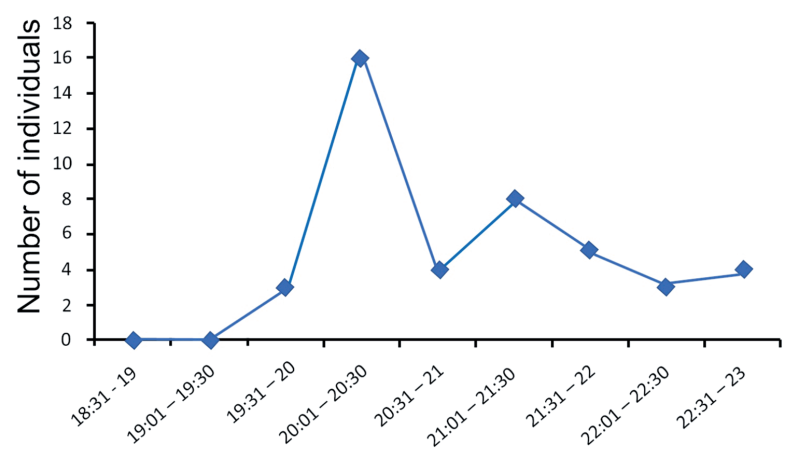

Day time (hour)

Figure 4. Daily above-ground activity pattern of Cyrtodactylus gialaiensis from the study area in Vietnam. 
of sexual size dimorphism (although the females had the head larger than the males), and with a thermal ecology consistent with that of a nocturnal lizard. Indeed, our thermoregulation statistical tests showed that $C$. gialaiensis is a clear nocturnal thermoregulator with body temperatures that were significantly higher than substratum temperatures. Unfortunately, the relatively small sample sizes impeded us to obtain data that can be quantitatively compared with other Cyrtodactylus species or with other tropical geckos.

Our study pointed out both positive and negative evidences for the conservation of this endemic lizard. The positive evidence was that the species was relatively common, and surely one of the most readily encountered reptile species at the study area. The adult population size $(n=117)$ is almost certainly underestimated by our applied methodology as we could not properly evaluate the occupancy rates and the detectability values. The negative evidence was that, anyway, these geckos were apparently selective in their habitat choice, and were found only in two of the seven habitat types. Surprisingly, they were not observed at all in the mature and secondary forests, where in theory their presence was apriori expected. Thus, this species has not only an extremely reduced range, but also a narrow habitat niche, with its preferred habitats being heavily altered and exposed to human pressure (road sides nearby plantations). These aspects would indicate that $C$. gialaiensis has a high risk of extinction, and needs immediate conservation attention by the relevant authorities. We would recommend that domestic animals, and especially feral cats and dogs, should be impeded to freely move throughout the small area inhabited by this species, as it is well known that these mammals, and especially the cats, can easily destroy whole populations of wild lizards and other reptiles (e.g., Barratt 1997; Baker et al. 2005; Li et al. 2014).

\section{Acknowledgements}

The authors are grateful to the directorates of the Forest Protection Department of Gia Lai Province and Chu Se People Committee for supporting their field work and issuing relevant permits. They thank Khanh Q. Nguyen and Long T. Nguyen for their assistance in the field survey. Two anonymous reviewers critically commented and improved the submitted draft, and Dr Daniele Dendi prepared Figures 3 and 4.

\section{Conflicts of interest/Funding}

This research was supported by the Mohamed bin Zayed Species Conservation Fund (Project Number: 192521666). The authors declare no conflict of interest.

\section{Contributions}

VQL planned the study; LL and VQL designed the methodology; VQL, OLV, TTH, TPV, OLD collected the data; GA and LL analyzed the data; GA, LL, CB, BL and VQL drafted the manuscript; all authors revised and approved the various drafts.

\section{References}

Bailey NTJ. 1981. Statistical Methods in Biology. London: English Universities Press. IX+199 pp. Baker PJ, Bentley AJ, Ansell RJ, Harris S. 2005. Impact of predation by domestic cats Felis catus in an urban area. Mammal Review. 35:302-312. 
Barratt DG. 1997. Predation by house cats, Felis catus (L.), in Canberra, Australia. I. Prey composition and preference. Wildlife Research. 24:263-277.

Bauer AM. 2013. Geckos:The Animal Answer Guide. Baltimore (MD): Johns Hopkins University Press. 159 pp.

Chu Se People Committee. 2019. Report on status of economic, nature geography condition, and social condition of Chu Se district, Gia Lai Province. 10 pp. (in Vietnamese).

David P, Nguyen QT, Schneider N, Ziegler T. 2011. A new species of the genus Cyrtodactylus Gray, 1827 from central Laos (Squamata: Gekkonidae). Zootaxa. 2833:29-40.

Grismer LL, Wood Jr PL, Quah ES, Murdoch ML, Grismer MS, Herr MW, Espinoza RE, Brown R.M, Lin A. 2018a. A phylogenetic taxonomy of the Cyrtodactylus peguensis group (Reptilia: Squamata: Gekkonidae) with descriptions of two new species from Myanmar. PeerJ. 6:e5575.

Grismer LL, Wood Jr PL, Thura MK, Quah ES, Murdoch ML, Grismer MS, Herr MW, Lin A, Kyaw H. 2018b. Three more new species of Cyrtodactylus (Squamata: Gekkonidae) from the Salween Basin of eastern Myanmar underscore the urgent need for the conservation of karst habitats. Journal of Natural History. 52:1243-1294.

Huang C, Ning J. 2006. Summer habitat characteristics of the Chinese Crocodile Lizard (Shinisaurus crocodilurus) in the Luokeng Nature Reserve, Guangdong. Zoological Research. 27:419-426.

Huang CM, Yu H, Wu Z, Li YB, Wei FW, Gong MH. 2008. Population and conservation strategies for the Chinese crocodile lizard (Shinisaurus crocodilurus) in China. Animal Biodiversity and Conservation 31:63-70.

Huang W. 2006. Ecological characteristics of the skink, Mabuya longicaudata, on a tropical East Asian island. Copeia. 2006:293-300.

IUCN. 2020. The IUCN red list of threatened species. Available at: <www.iucnredlist.org>. Last accessed: 15 May 2020.

Li B, Belasen A, Pafilis P, Bednekoff P, Foufopoulos J. 2014. Effects of feral cats on the evolution of anti-predator behaviours in island reptiles: insights from an ancient introduction. Proceedings of the Royal Society B: Biological Sciences. 281(1788):20140339.

Lombardi CM, Hurlbert SH. 1996. Sunfish cognition and pseudoreplication. Animal Behaviour. 52:419-422.

Luu VQ. 2018. Cyrtodactylus gialaiensis. The IUCN Red List of Threatened Species 2018: e.T125554212A125554215. http://dx.doi.org/10.2305/IUCN.UK.2018-2.RLTS.T125554212A1255 54215.en.

Luu VQ, Dung T, Nguyen TQ, Le MD, Ziegler T. 2017. A new species of the Cyrtodactylus irregularis complex (Squamata: Gekkonidae) from Gia Lai Province, Central Highlands of Vietnam. Zootaxa. 4362:385-404.

Meek R. 2005. Null models and the thermal biology of the anguid lizard Anguis fragilis; evidence for thermoregulation? Amphibia-Reptilia. 26:445-450.

Ngo HN, Nguyen TQ, Nguyen T, Barsch F, Ziegler T, van Schingen M. 2016. First population assessment of the endemic insular Psychedelic Rock Gecko (Cnemaspis psychedelica) in southern Vietnam with implications for conservation. Amphibian and Reptile Conservation. 10:18-26.

Ngo HN, Nguyen TQ, Van Nguyen T, Van Schingen M, Ziegler T. 2018. Microhabitat selection and communal nesting in the insular Psychedelic Rock Gecko, Cnemaspis psychedelica, in Southern Vietnam with updated information on trade. Nature Conservation. 31:1.

Nguyen TQ, Kingsada P, Rosler H, Auer M, Ziegler T. 2010. A new species of Cyrtodactylus (Squamata: Gekkonidae) from northern Laos. Zootaxa. 2652:1-16.

Nguyen TQ, Le MD, Pham A, Ngo HN, Hoang C, Pham C, Ziegler T. 2015. Two new species of Cyrtodactylus (Squamata: Gekkonidae) from the karst forest of Hoa Binh Province, Vietnam. Zootaxa. 3985:375-390.

Nguyen NS, Orlov NL, Darevsky IS. 2006. Descriptions of two new species of the genus Cyrtodactylus Gray, 1827 (Squamata: Sauria: Gekkonidae) from Southern Vietnam. Russian Journal of Herpetology. 13:215-226.

Panitvong N, Sumontha M, Tunprasert J, Pauwels OS. 2014. Cyrtodactylus saiyok sp. nov., a new dry evergreen forest-dwelling Bent-toed Gecko (Squamata: Gekkonidae) from Kanchanaburi Province, western Thailand. Zootaxa. 3869:64-74. 
Schneider N, Nguyen QT, Schmitz A, Kingsada P, Auer M, Ziegler T. 2011. A new species of Cyrtodactylus (Squamata: Gekkonidae) from northwestern Laos. Zootaxa. 2930:1-21.

Uetz H. 2020. Cyrtodactylus genus [WWW Document]. URL http://reptiledatabase.reptarium.cz/search?search $=$ cyrtodactylus $+\&$ submit $=$ Search (accessed 10 May 2020). Xiao F, Wang J, Long Z, Shi H. 2017. Diet of Two Endangered Box Turtles (Cuora spp.) on Hainan Island, China. Chelonian Conservation and Biology. 16:236-238. 